\title{
Bag1 is a regulator and marker of neuronal differentiation
}

\author{
P Kermer ${ }^{1}$, M Krajewska ${ }^{1}$, JM Zapata ${ }^{1}$, S Takayama ${ }^{1}$, J Mai ${ }^{1,2}$, \\ S Krajewski ${ }^{\star, 1}$ and JC Reed ${ }^{\star, 1}$ \\ ${ }^{1}$ The Burnham Institute, Program on Apoptosis and Cell Death Research, 10901 \\ N. Torrey Pines Road, La Jolla, California, CA 92037, USA \\ ${ }^{2}$ Heinrich-Heine Universität Düsseldorf, Department of Neuroanatomy, \\ Moorenstrasse 5, D-40001 Düsseldorf, Germany \\ *Corresponding authors: JC Reed and S Krajewski, The Burnham Institute, \\ 10901 N. Torrey Pines Road, La Jolla, CA 92037, USA. Tel: (858) 646-3100; \\ Fax: (858) 646-3194; E-mail: jreed@burnham.org and stan@burnham.org
}

Received 10.6.01; accepted 10.10.01

Edited by DR Green

\begin{abstract}
Bag 1 acts as a co-chaperone for $\mathrm{Hsp} 70 / \mathrm{Hsc70}$. We report here that stable over-expression of Bag1 in immortalized neuronal CSM14.1 cells prevents death following serum deprivation. Bag1 over-expression slowed the proliferative rate of CSM14.1 cells, resulted in increased levels of phospo-MAP kinases and accelerated neuronal differentiation. Immunocytochemistry revealed mostly nuclear localization of Bag1 protein in these cells. However, during differentiation in vitro, Bag1 protein shifted from predominantly nuclear to mostly cytosolic in CSM14.1 cells. To explore in vivo parallels of these findings, we investigated Bag1 expression in the developing mouse nervous system using immunohistochemical methods. Early in brain development, Bag1 was found in nuclei of neuronal precursor cells, whereas cytosolic Bag1 staining was observed mainly after completion of neuronal precursor migration and differentiation. Taken together, these findings raise the possibility that the Bag1 protein is expressed early in neurogenesis in vivo and is capable of modulating neuronal cell survival and differentiation at least in part from a nuclear location.

Cell Death and Differentiation (2002) 9, 405-413. DOI: 10.1038/ sj/cdd/4400972
\end{abstract}

Keywords: neuronal differentiation; Bag1; CSM 14.1 cells; mouse brain development; apoptosis; neuroprotection

Abbreviations: Bag1, Bcl-2-associated athanogene-1; NSE, neuron-specific endlase; MAPK, mitogen-activated protein kinase

\section{Introduction}

Bag1 (Bcl-2-associated athanogene-1) is the first identified member of a family of Hsp70-binding proteins containing a conserved C-terminal region termed the 'Bag domain'. ${ }^{1-3}$ The Bag domain binds tightly to the ATPase domain of the Hsp70 family of molecular chaperones and regulates their activity. Diversity in the $\mathrm{N}$-terminal regions of BAG-family proteins permits their association with specific target proteins or targeting to subcellular locations.
Bag1 was identified by virtue of its ability to bind and collaborate with Bcl-2 in suppressing cell death. ${ }^{1}$ Since then, multiple functions have been reported for Bag1, including interactions with the serine/threonine-specific protein kinase Raf, some tyrosine kinase growth factor receptors, and several steroid hormone receptors. ${ }^{4-6}$ At the cellular level, over-expression of Bag1 can result in various phenotypes, including enhanced tumor cell proliferation, promotion of cell motility and metastasis, and increased resistance to apoptosis. ${ }^{1,2,5,7-14}$

Programmed cell death or apoptosis is a crucial feature ensuring proper development and differentiation of the nervous system. Moreover, in response to many injuries, such as stroke, neurodegenerative disease and trauma, differentiated neurons are known to induce the expression of stress proteins, including heat shock proteins. ${ }^{15,16}$ Bag1 is expressed in the developing and mature mammalian nervous system. ${ }^{17,18}$ However, detailed information about the expression and function of Bag1 during neuronal development, differentiation and death is currently limited. For example, Bag1 has been shown to prevent apoptosis in PC12 cells in vitro when over-expressed together with $\mathrm{Bcl}-2 .^{9} \mathrm{~A}$ similar synergistic effect of Bag1 and $\mathrm{Bcl}-2$ has been demonstrated in an in vivo model of photoreceptor cell death involving transgenic mice expressing these genes under the control of the rod opsin promoter. ${ }^{19}$ Furthermore, loss of Bag1 immunoreactivity in the rat brain after transient middle cerebral artery occlusion ${ }^{20}$ and in olfactory neurons following synaptic target ablation ${ }^{21}$ suggests a potential role for Bag1 in suppression of neuronal death.

Two isoforms of the mouse Bag1 protein resulting from alternative translation initiation codon selection within a single mRNA have been reported. ${ }^{22}$ In contrast to the human Bag1 protein, little is known about the intracellular location of these two proteins. In the present study, we demonstrate that when stably over-expressed in the immortalized neuronal cell line CSM14.1, the short p29 form of mouse Bag1 resides predominantly in the nucleus. Bag1 not only prevents neuronal death but also promoted neuronal differentiation in vitro in these cells. During differentiation, Bag1 protein accumulated in the cytosol of CSM14.1 cells, becoming absent from the nucleus. An analysis of Bag1 expression during neuronal development in the mouse in vivo revealed similar patterns of Bag1 protein expression and intracellular location when compared to neuronal differentiation in vitro. The findings suggest that Bag1 is capable of modulating neuronal death and differentiation from a nuclear location.

\section{Results}

\section{Over-expression of mBag1 in neuronal CSM14.1 cells}

To over-express Bag1 in neuronal cells, we transfected CSM14.1 neuronal cells ${ }^{23}$ with a plasmid containing flag- 
tagged mouse p29 Bag1 driven by the neuron-specific enolase (NSE) promoter (Figure 1A). In a co-transfection, we introduced pBabePURO containing a puromycin resistance gene as selection marker. The plasmid containing a NSE-driven luciferase gene served as control vector. Prior to and after selection of single cell clones, gene expression was checked by immunoblot analysis employing antibodies against Bag1 (Bur 1680 and 1735) and Flag. Flag-mBag1, which migrates in gels at a slightly higher molecular weight than endogenous Bag1, was strongly expressed (Figure 1B). Out of 30 clones tested, 12 were positive for over-expression of Bag1. Two clones (\#15 and 20) were chosen for further analysis.

\section{Localization of Bag1 protein in CSM14.1 cells}

To explore the intracellular location of Bag1 in CSM14.1 neuronal cells, we performed immunofluorescence microscopy analysis of our stably-transfected cells, employing two antibodies raised against different epitopes of Bag1. Compared to the levels of endogenous Bag1 expression in CSM14.1 cells, we observed a striking increase in nuclear immunofluorescence in cells over-expressing Bag1 (Figure $1 \mathrm{C})$. In contrast, staining with preimmune serum and rabbit IgG produced no immunofluorescence, demonstrating the specificity of these results (not shown).

To verify our findings, we applied an antibody against Flag. As shown in Figure 1C, the tagged version of Bag1 was detected mainly in the nucleus of Bag1-transfected cells. In contrast, no immunofluorescence was observed in control-transfected CSM14.1 cells using anti-Flag antibody (Figure 1C).

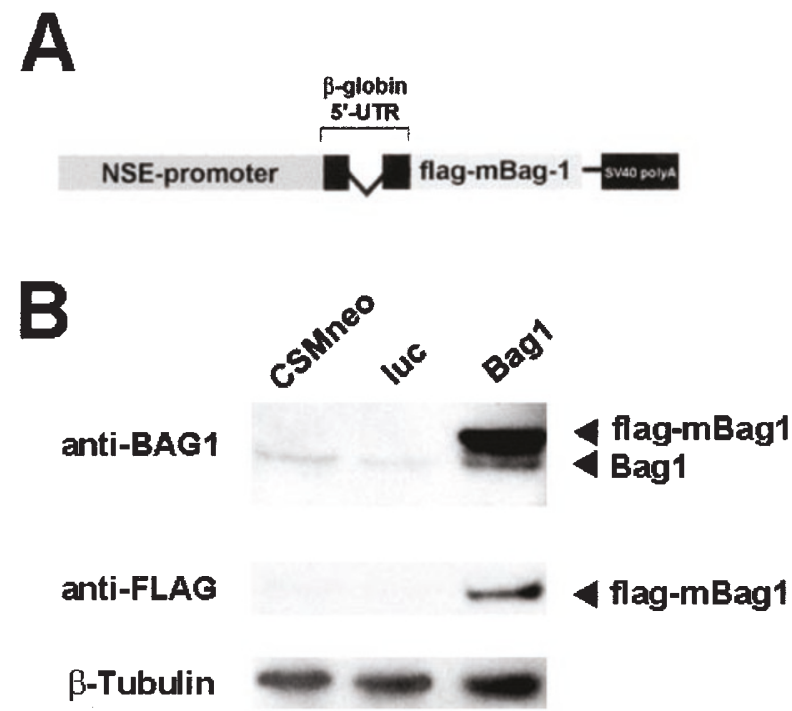

\section{Bag1 inhibits cell death after serum starvation}

Serum starvation induces death of CSM14.1 cells maintained at $39^{\circ} \mathrm{C}^{23}$ After 2 days without serum, approximately $40 \%$ of wild-type cells were dead (Figure 2). This death can be largely attributed to apoptosis, since cells displayed fragmented nuclei (as visualized by DAPI staining) and could be protected by treatment with the broad-spectrum caspase inhibitor zVAD-fmk (data not shown). As shown in Figure 2, stable Bag1 over-expression significantly prevented cell death measured at 24 and $48 \mathrm{~h}$ after serum deprivation $(P<0.01)$, while transfection with control vector (CSMluc) did not. Both of the stably-transfected clones tested, Bag15 and Bag20, which express the transgene at comparable levels (see insert in Figure 2), displayed substantially reduced cell death rates ( $50 \%$ ) when compared to control-transfected cells.

Since cell death prevention by stable over-expression of $\mathrm{Bcl}-2$ in CSM14.1 cells has been reported previously, ${ }^{23}$ we also compared Bag1 transfectants to $\mathrm{Bcl}-2$ over-expressing CSM14.1 cells. As shown, Bcl-2 proved to be more effective than Bag1, abolishing cell death following serum deprivation almost completely (Figure 2).

\section{Bag1 induces differentiation of CSM14.1 cells}

We observed changes in morphology of Bag1 overexpressing cells even when cultured at the 'permissive' temperature of $32^{\circ} \mathrm{C}$. In contrast to the small and round shape of wild-type cells, Bag1 over-expressing cells look larger and display a more polarized shape (not shown, compare Figure 1C).

Since differentiation of CSM14.1 cells is known to occur after switching temperature to $39^{\circ} \mathrm{C},{ }^{23}$ we suspected that

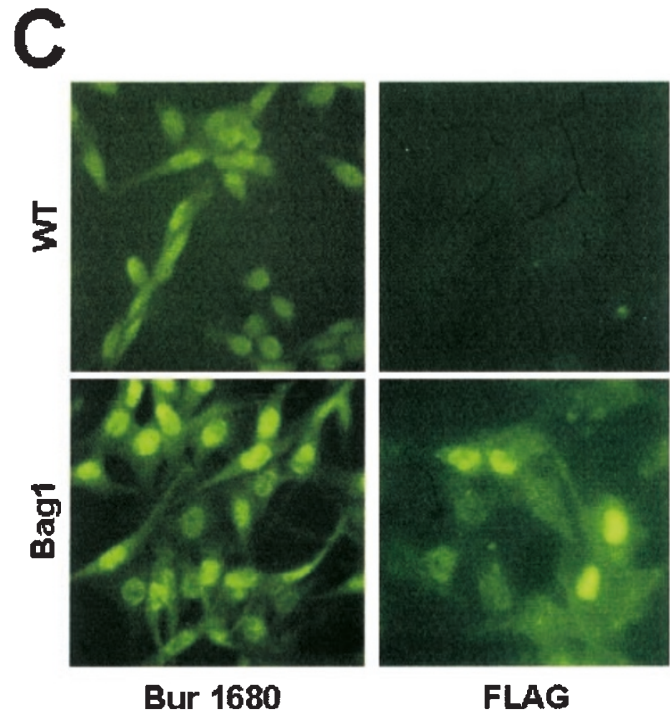

Figure 1 Generation of Bag1 over-expressing cells. (A) Cells were stably transfected with a plasmid containing the flag-tagged sequence of mouse Bag1 under control of the neuron-specific enolase promoter (NSE). (B) Immunoblot analysis of lysates (20 $\mu$ g per lane) from wild-type anti-FLAG (CSMneo), empty vectortransfected (luc) and Bag1-transfected (Bag1) CSM14.1 cells prior to isolating clones, developed with anti-Bag1 antiserum Bur 1680 and visualized by ECL reagent on nitrocellulose membranes. The plasmid-derived flag-mBag1 and endogenous Bag1 are indicated by arrowheads. (C) Immunufluoresence microscopy was performed employing polyclonal Bag1 antiserum or monoclonal anti-FLAG antibody, followed by FITC-labeled secondary antibody (400 $\times$ magnification). Upper row shows control-transfected cells (WT), revealing nuclear and cytoplasmic expression of endogenous Bag1. No signal was detected with FLAG antibody. In contrast, Bag1 immunofluorescence in stable transfectants (lower row, Bag1) is strongly increased with predominantly nuclear localization of flag-mBag1 revealed by staining with the anti-FLAG antibody 


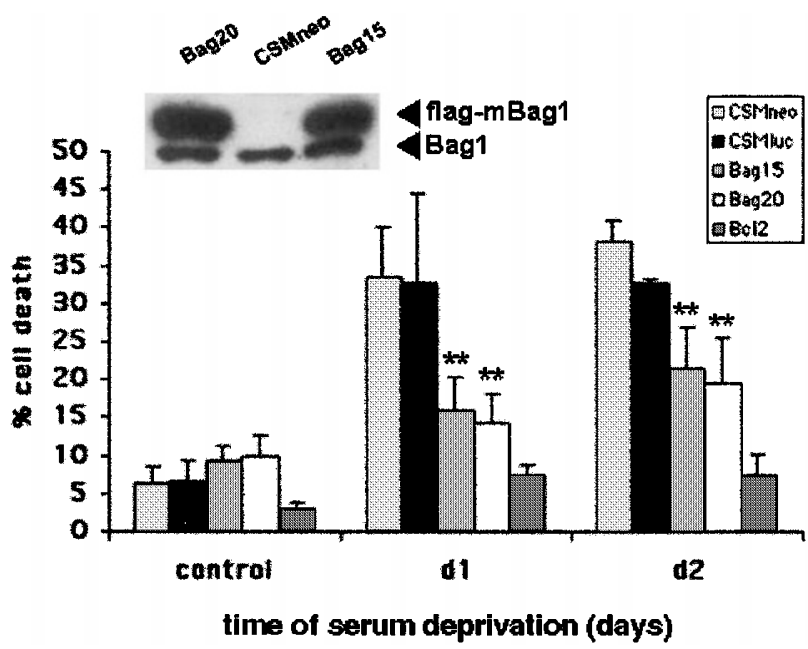

Figure 2 Bag1 is protective after serum deprivation. Cells were maintained at 'non-permissive' temperature for $2-3$ days prior to serum-deprivation. Cell death was assessed by Trypan Blue exclusion assay (mean + s.d.; $n=6$ ). Two clones (15 and 20) expressing comparable levels of flag-mBag1 were analyzed (see insert). ${ }^{* *}$ significant when compared to CSMneo $(P<0.01)$

Bag1 might promote differentiation of these cells. Since neuronal differentiation is associated with a cessation of cell proliferation, we first assessed the doubling time of control and Bag1 over-expressing CSM14.1 cells. We found a highly significant difference in the generation times of the respective cell lines at $32^{\circ} \mathrm{C}(P<0.01)$. Cells overexpressing Bag1 were less proliferative, with an average generation time of $42 \mathrm{~h}$, whereas wild-type CSM14.1 and empty vector transfected cells doubled on average every $25 \mathrm{~h}$ (Figure 3A).

To further explore the effects of Bag1 on differentiation of CSM14.1 cells, experiments were performed in which CSM14.1 cells were switched to non-permissive temperature of $39^{\circ} \mathrm{C}$ (where the SV40 large T-antigen is inactive) and cell morphology was compared at various times thereafter. Figure 3B, for example, contrasts the morphology of wild-type and Bag1 over-expressing cells at two different times after switching to $39^{\circ} \mathrm{C}$. After 8 days at $39^{\circ} \mathrm{C}$, most wild-type and control-transfected CSM14.1 cells had an enlarged cell soma containing a big nucleus. However, few of these cells had started to extend axon-like processes. In contrast, in cultures of Bag1 over-expressing cells, almost all of the cells were much smaller in size and assumed a more polarized shape. Virtually all of these cells had grown processes, which often aligned, forming bundles. Measurement of the length of these processes after 8 days at non-permissive temperature revealed that axon-like structures in Bag1 over-expressing cells had grown almost three times longer than processes in wildtype cells $(P<0.01$; Figure $3 \mathrm{C})$. After extended periods at $39^{\circ} \mathrm{C}$, the morphological differences became even more pronounced. After 21 days at non-permissive temperature, Bag1 over-expressing cells were characterized by striking arborization of processes and formation of dense nests of axon-like connections between cells. In contrast, cells in cultures of wild-type or control-transfected cells had a less differentiated appearance, with residual large cells and far fewer cellular processes (Figure 3B).

To correlate these differences in morphological changes with markers of the neuronal phenotype, we investigated the expression of neuronal differentiation-associated proteins in these cell lines. After extended time at nonpermissive temperature, weak Neurofilament-200 staining could be detected in cultures of either control- or Bag1 over-expressing CSM14.1 cells (data not shown). In contrast, positive staining for NeuN antigen (a marker of post-mitotic neuronal nuclei) was observed in most Bag-1 over-expressing cells by day 21 at $39^{\circ} \mathrm{C}$, while $\mathrm{NeuN}$ staining was very weak or completely absent in control CSM14.1 cells (Figure 3D).

Interestingly, during neuronal differentiation at nonpermissive temperature, there was a loss of nuclear Bag1 expression. Figure 3E illustrates the localization of Bag1 in stably transfected CSM14.1 cells after 28 days at nonpermissive temperature using polyclonal antiserum against Bag1 (Bur 1680). In contrast to the mainly nuclear location of flag-mBag1 at permissive temperature (compare Figure 1C), most Bag1-transfectants over-expressing cells display an exclusively cytosolic location of Bag1, as revealed by double-labeling with DAPI (Figure 3E). As before, staining with preimmune serum and control rabbit IgG served as negative controls (not shown).

\section{Bag1 over-expression induces MAPK-pathway}

Given the accelerated differentiation of Bag1 over-expressing cells after switch to non-permissive temperature we hypothesized that the activation of MAP kinases, known to be important players in neuronal differentiation, contributes to this phenotype. As shown in Figure 4, Bag1 over-expressing cells showed increased levels of phospho-Erk1/2 at permissive temperature of $32^{\circ} \mathrm{C}$ when compared to wild-type cells. These high levels of Erk1 and 2 phosphorylation were maintained after switch to $39^{\circ} \mathrm{C}$. In wild-type cells, only a modest increase in Erk-phosophorylation could be detected following temperature switch, while the expression of nonphosphorylated Erks did not change significantly in both cell types over time. Interestingly, the temperature switch induced increased levels of Hsp70 with similar kinetics in both wildtype and Bag1 over-expressing cells (Figure 4).

\section{Bag1 expression during development of the mouse nervous system}

Bag1 expression in the developing mouse nervous system was studied using immunohistochemical methods. At the onset of neurulation (E7.5-8), neural folds in the cephalic region contained only trace levels of Bag1 immunostaining. A single layer of pseudostratified columnar epithelium, constituting the neuroepithelium of the primitive neural tube, exhibited barely detectable cytosolic Bag1 staining (Figure $5 A)$. With the formation of the three primary brain vesicles at E8.5-9.5, Bag1 nuclear staining appeared and was located predominantly in the differentiating neuroblasts of the rhombencephalon and mesencephalon, and at lower levels 

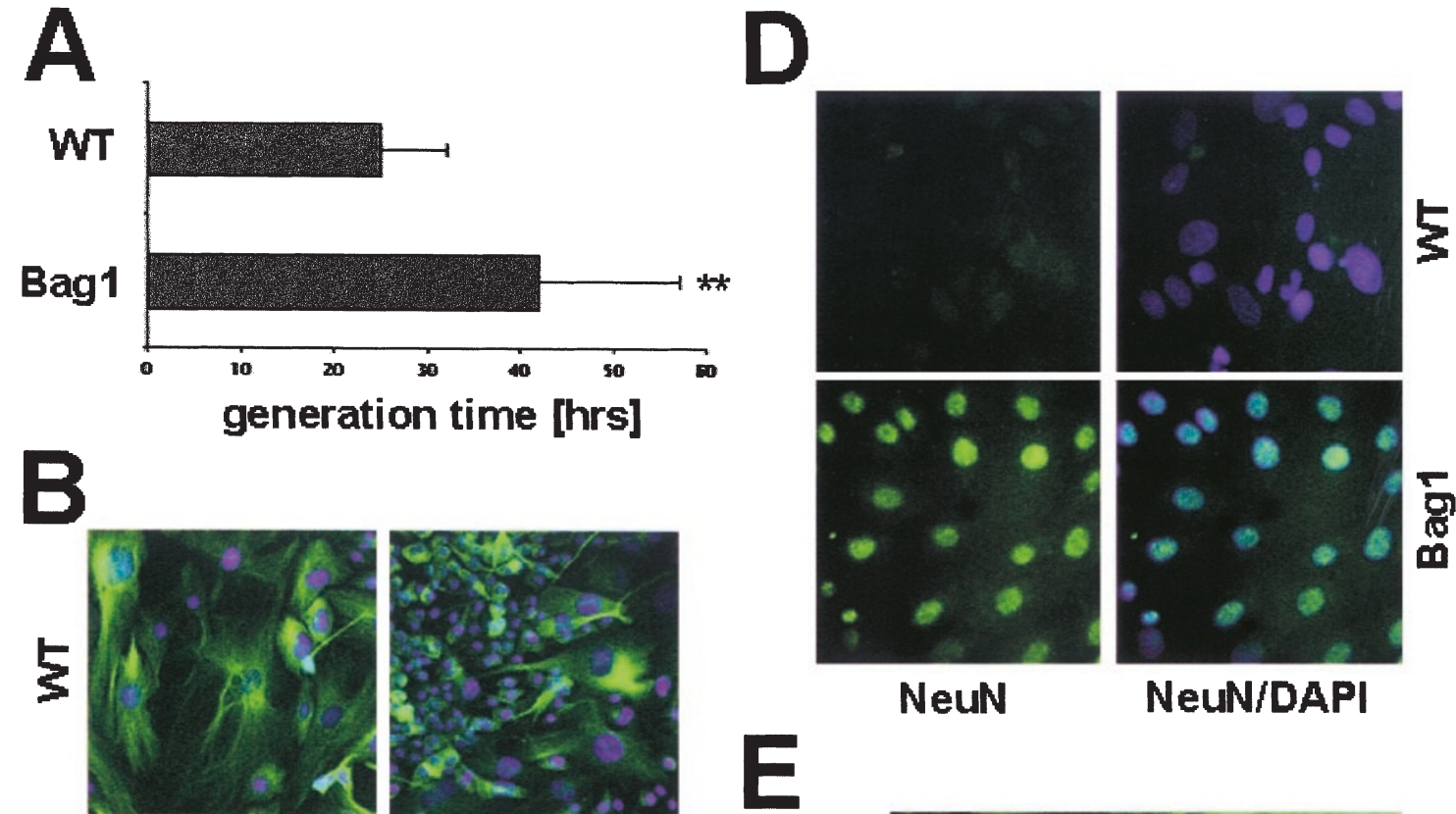

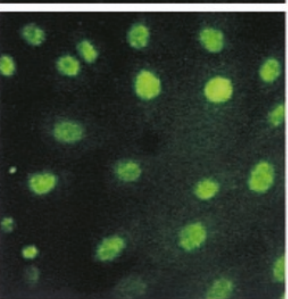

NeuN

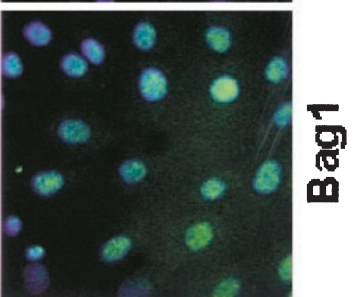

NeuN/DAPI

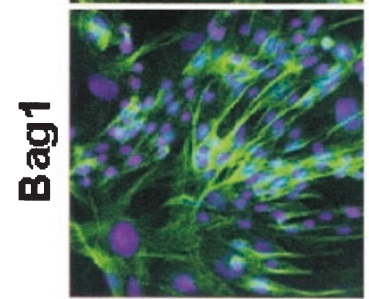

day 8

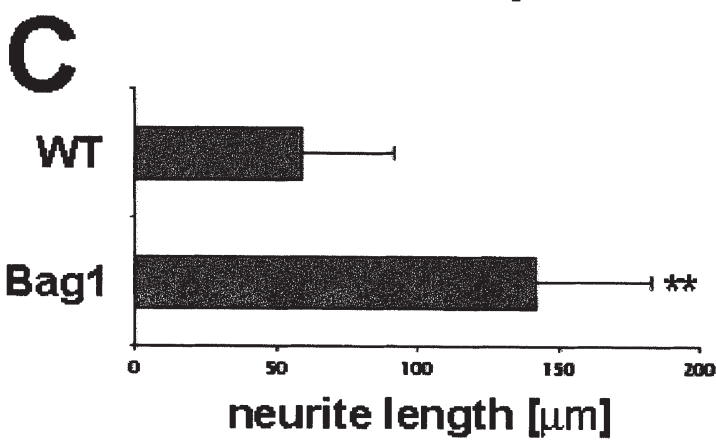

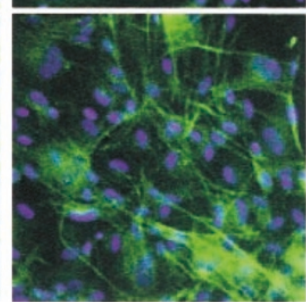

day 21

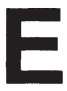

Bur

1680
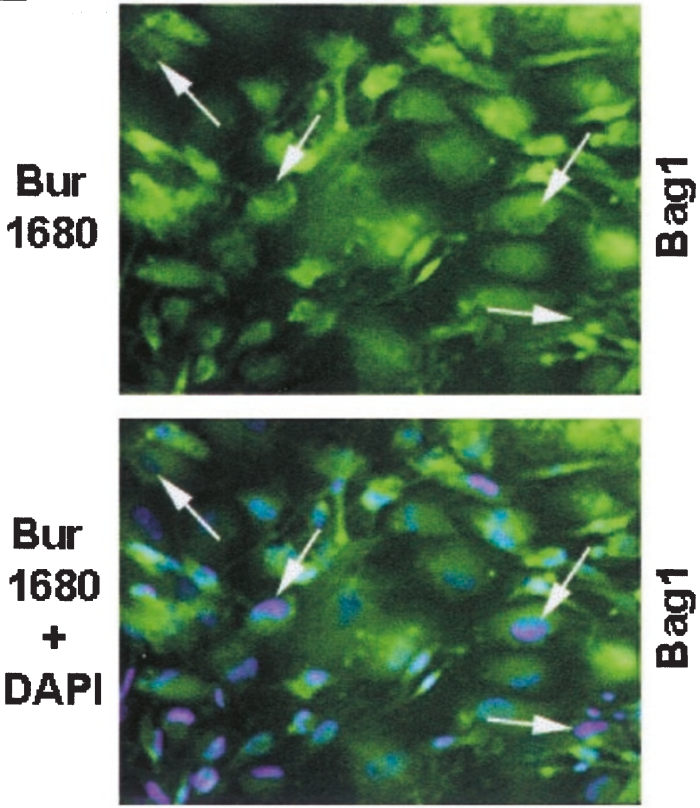

Figure 3 (A) Bag1 induces neuronal differentiation in vitro. Generation time was assessed by counting cell numbers during logarithmic growth at permissive temperature $\left(32^{\circ} \mathrm{C}\right)$ over 1 week. Data were averaged for wild-type and control-transfected (WT) as well as two independent Bag1 over-expressing clones (Bag1). Average generation time (mean \pm s.d., $n=3$ ) was significantly higher in Bag1 over-expressing cells $(P<0.01)$. (B) Immunostaining was performed using anti-Tubulin antibody (visualized with FITC-coupled secondary antibody). Cells were co-stained with DAPI. Photomicrographs show wild-type or control-transfected (upper row, WT), and Bag1 over-expressing cells (lower row, Bag1) on day 8 and 21 after switching to 'non-permissive' temperature (200 $\times$ magnification). Note the morphologically advanced stage of Bag1 over-expressing cells with formation of dense nests of cellular processes on day 21. (C) Measurement of neurite extension in Bag1 over-expressing versus wild-type or control-transfected cells on day 8 after switch to $39^{\circ} \mathrm{C}$. Data represent mean $\pm s$.d. ( $n=75$ cells measured from three independent experiments). Processes are significantly longer in Bag1 over-expressing cells $(P<0.01)$. (D) WT (upper row) and Bag1 over-expressing (lower row) cells were fixed after 28 days culture at $39^{\circ} \mathrm{C}$ and stained using FITC-labeled NeuN and DAPI ( $400 \times$ magnification). While NeuN staining in WT cells is absent or very faint, almost all nuclei in Bag1 over-expressing cells expressed the NeuN antigen. (E) Bag1 over-expressing cells (Bag1) were fixed after 28 days culture at $39^{\circ} \mathrm{C}$ and stained using polyclonal Bag1 antibody (Bur 1680, upper panel) followed by detection with FITC-anti-rabbit IgG. The same sample was stained with DAPI to reveal nuclei. As shown in the upper panel, Bag1 immunofluorescence is excluded from the nuclear region of differentiated CSM14.1 cells (arrows). Staining with DAPI confirmed that the Bag1-negative regions corresponded to nuclei (lower panel)

in the prosencephalon (Figure 5B,C). Numerous neuroblasts in the caudal part of the neural tube (which subsequently differentiates into the spinal cord) contained moderate levels of Bag1 nuclear labeling (Figure 5D). 


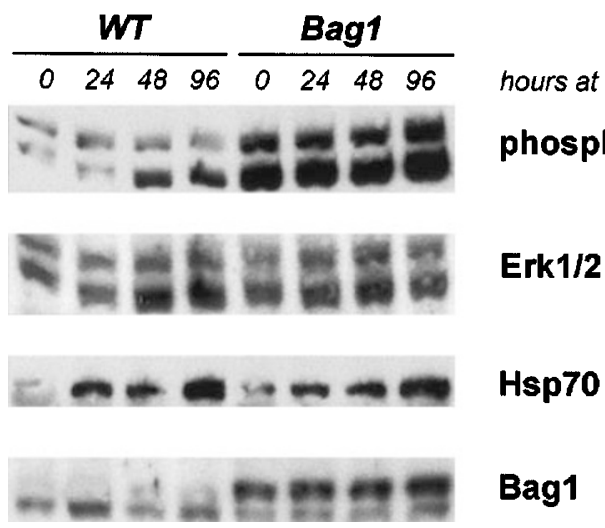

Figure 4 Bag1 over-expression activates MAPK pathway. Lysates of wildtype (WT) and Bag1 over-expressing (Bag1) cells at different time-points after switch to $39^{\circ} \mathrm{C}$ were subjected to SDS-PAGE and analyzed by immunoblot incubating the same membrane sequentially with phospho-Erk1/2, Hsp70, Bag1 and Erk1/2 antibodies. Bag1 over-expressing cells displayed markedly increased levels of phospho-Erk1/2

At a later stage of neural differentiation (E10-11), when the division of the primitive neural tube into three concentric layers occurs, neuroblasts in proliferative, periventricular matrix zone were consistently negative for Bag1. An obvious gradient of Bag1 expression appeared at this stage, associated with differentiation of the peripherally migrating progeny of ventricular neuroblasts to the intermediate mantle layer. The cells with early features of neuronal differentiation in the mantle layer, which gives rise to the gray matter of the central nervous system, demonstrated strong nuclear Bag1 immunostaining (Figure $5 \mathrm{E})$.

At E12, when the various regions of the brain are more clearly defined, roughly half of the migrating postmitotic neurons evidenced not only intense nuclear staining but also increasing cytoplasmic Bag1 immunoreactivity (Figure $5 \mathrm{~F}$ ) in the hypothalamus, thalamus, and corpus striatum (the major derivatives of the diencephalon). At this time, a significant increase of Bag1 immunoreactivity also became apparent in the developing peripheral nervous system. Strong nuclear labeling was evident in the differentiating sensory neurons of the dorsal root ganglia (Figure 5G), and in the segmental ganglia along sympathetic trunks. The cranial ganglia, such as the facial (VII), acoustic (VIII), and the glossopharyngeal (IX) ganglion complexes revealed a similar distribution pattern (data not shown).

By E13-14 in the central nervous system of developing embryos, differentiating neuroblasts in the neopallial cortex (which is formed as cells from the mantle layer of the telencephalic vesicles migrate into the overlying marginal zone to constitute in due course the outer gray layer of the cerebral hemispheres) contained moderate levels of cytosolic Bag1, whereas the intensity of the nuclear signal had greatly declined. In the forming hippocampal plate, nuclear Bag1 immunoreactivity remained only in the rare residual migrating neuroblasts throughout most of the thickness of the plate (data not shown). This trend toward diminishing nuclear and increasing cytosolic Bag1 immunostaining in more differentiated neurons continued throughout the remaining nervous system development in multiple regions of the brain and peripheral nervous system, including the spinal cord (Figure $5 \mathrm{H}, \mathrm{J}$ ), sympathetic trunk ganglia (Figure 5), olfactory bulb, pyramidal neurons of the CA3-CA4 sector of the hippocampus (Figure $5 \mathrm{~K}, \mathrm{~L}$ ), diencephalons, mesencephalon and rhombencaphalon as well as the retina (Figure $5 \mathrm{M}, \mathrm{N}$ ). Control stainings performed with preimmune serum or using anti-Bag1 antibody that had been pre-adsorbed with Bag1 protein or peptide antigen confirmed the specificity of these results (Figure 50, not shown).

During the later fetal life and into adulthood, selected types of neurons retained Bag1 expression, which was predominantly localized to the cytosol.

\section{Discussion}

Bag1 is an anti-apoptotic protein capable of binding to Bcl-2. Recently, binding of Bag1 to a variety of other intracellular proteins linking cell signaling, cell death and cellular stress responses has been shown. ${ }^{3}$ In the present report, we suggest a new function of Bag1 as a regulator of neuronal differentiation in vitro and as a marker of neuronal differentiation in vivo in the developing mouse nervous system.

For our in vitro studies, we used the neuronal cell line CSM14.1 which originated from rat nigral neurons immortalized by expression of temperature-sensitive SV40 large $\mathrm{T}$ antigen. These cells show a high proliferative rate at permissive temperature, while inactivation of large $T$ antigen at non-permissive temperature induces neuronal differentiation. ${ }^{23}$ Over-expression of $\mathrm{Bcl}-2$ in these cells has been shown to protect them from a variety of death stimuli, including serum starvation. ${ }^{23}$

To explore a potential role for Bag1 in the control of neuronal death, we stably over-expressed mouse Bag1 in CSM14.1 cells under the control of the neuron-specific NSE promoter. ${ }^{24}$ Over-expression of Bag1 significantly reduced apoptotic cell death induced by serum deprivation in cultures of CSM14.1 cells. Similarly, Bag1 has been shown to reduce cell death following growth factor withdrawal in 3T3 fibroblasts, $\mathrm{Ba} / \mathrm{F}$ hematopoietic cells and PC12 neural cells. ${ }^{1,7,9}$ In contrast, Roth and co-workers ${ }^{25}$ reported synergistic effects of Bag1 and Bcl-2, but no cyto-protective effects of Bag1 alone in a model of glioma cell death following serum starvation.

Besides cyto-protective effects, Bag1 over-expression in CSM14.1 cells promoted neuronal differentiation. Previously, the protein kinase Raf-1 has been shown to play an important role in neuronal differentiation. ${ }^{26}$ Bag1 interacts with Raf-1 and enhances its activity. ${ }^{6,27}$ The regions in Bag1 required for Raf-1-binding are overlapping with but distinct from those involved in Hsp70 binding. ${ }^{6,27}$ Raf kinase is a proximal element of the Ras-Raf-mitogenactivated protein kinases (MAPK) cascade. This pathway is a central effector of cellular differentiation during development ${ }^{28}$ and seems also to subserve memory and synaptic plasticity in the post-mitotic, mature nervous system. ${ }^{29}$ Consequently, Bag1 over-expressing neuronal cells displayed markedly increased levels of phospho-Erk1/2, the downstream kinases in the MAPK cascade. Interestingly, 

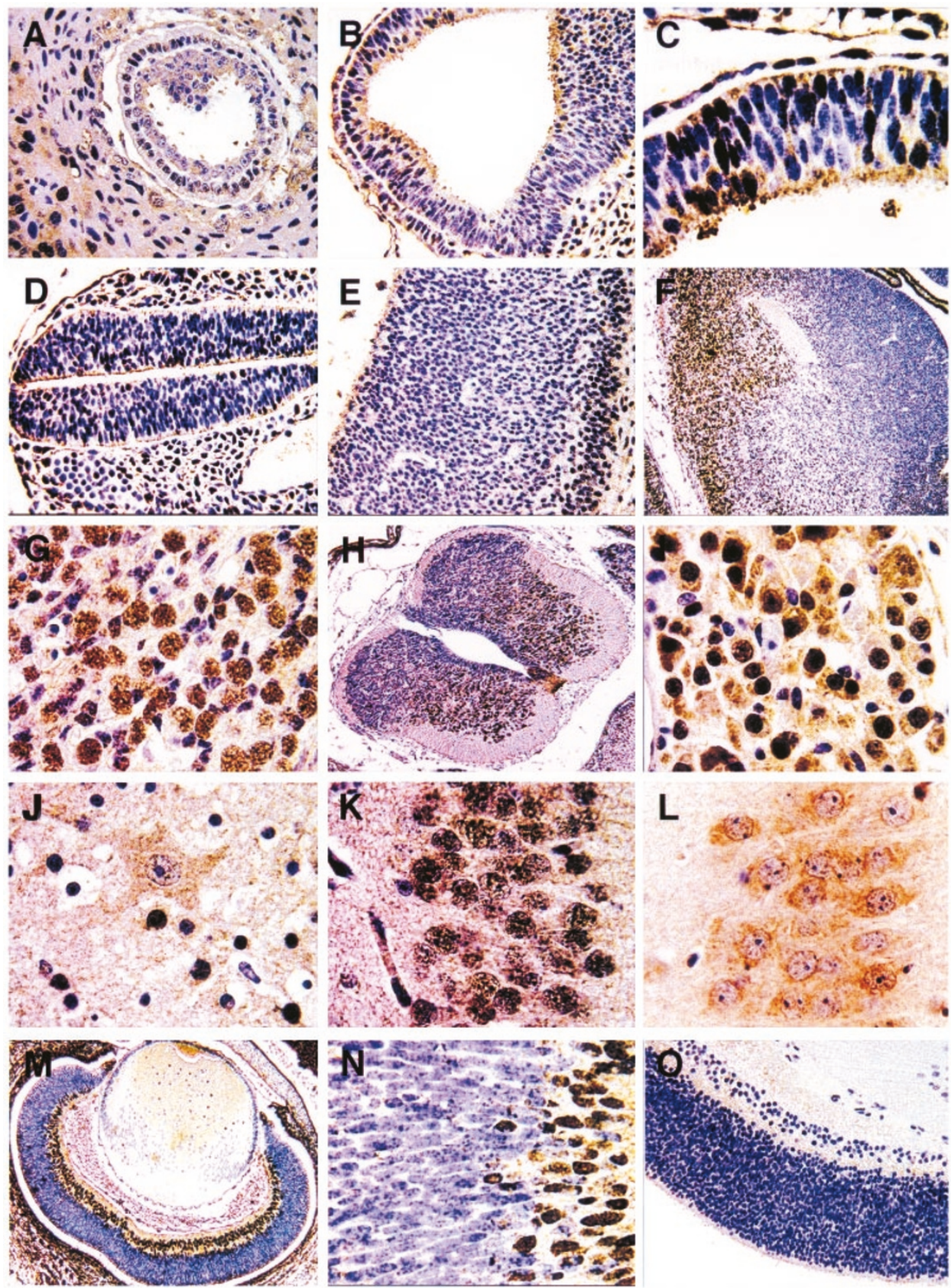

Figure 5 Bag1 expression in the developing nervous system of the mouse. Representative photomicrographs are shown for analysis of Bag1 expression in the mouse nervous system. Antibody detection was achieved using a DAB-based chromogenic method (brown) and nuclei were counterstained with hematoxylin. All results presented in this figure were obtained using a rabbit polyclonal antibody raised against a synthetic peptide (BUR1735), but similar results were observed using alternative antibodies (BUR1680 and 1702, not shown). (A) At the onset of neurulation (E7.5-8), the primitive neural tube exhibited barely detectable levels of cytosolic Bag1 (magnification $250 \times$ ). (B,C) At E8.5, Bag1 nuclear immunostaining appeared in the differentiating neuroblasts of the primary brain vesicles (magnification $250 \times$ and $1000 \times$, respectively). (D) At E8, neuroblasts in the caudal part of neural tube exhibit high levels of Bag1 nuclear expression (magnification $250 \times$ ). (E) Only occasional neuroblasts in the proliferative, periventricular matrix zone show Bag1 staining, whereas the differentiating neuronal cells in the mantle layer demonstrate strong Bag1 immunoreactivity (E11) (magnification $250 \times$ ). (F) The majority of neuronal cells in hypothalamus and basal part of corpus striatum demonstrate intense nuclear staining and increasing cytoplasmic signal for Bag1 (E12) (magnification 150 $\times$ ). (G) At E12, strong nuclear immunoreactivity is evident in the differentiating sensory neurons of the dorsal root ganglia (magnification $400 \times)$. (H) In the spinal cord (E14.5), note the elevated nuclear Bag1 immunoreactivity in the ventral motor neurons, and a negligible amount of this protein in the dorsal part (magnification $80 \times$ ). (I) An appearance of cytosolic immunostaining for this protein is noticed in the sympathetic trunk ganglia (E17) (magnification $400 \times$ ). (J) A terminally differentiated motor neuron in the spinal cord is shown, demonstrating loss of nuclear Bag1 staining at E17 (magnification 100 $\times$ ). High nuclear Bag1 expression in neurons of CA3 hippocampal sector in the later fetal stages (E17) (K; magnification $1000 \times$ ), down-regulated in their adult counterparts (L; (magnification 1000 x). (M,N) At E17, the outer-most, proliferating layer of primitive neuroepithelial cells in the retina is mostly immunonegative. The neuroblasts in the inner layer, which will differentiate into the ganglion cells, contain high levels of nuclear Bag1 (magnification $100 \times$ and $1000 \times$, respectively). (0) Control immunostaining using anti-Bag1 antiserum preadsorbed with $5 \mu \mathrm{g} / \mathrm{ml}$ of synthetic peptide immunogen showed negative staining of the neural retina (magnification $250 \times$ ) 
increased levels of active MAP kinases were already present at permissive temperature and associated with altered morphology of the cells. However, expression of neuronal differentiation markers could only be observed after switch to non-permissive temperature of $39^{\circ} \mathrm{C}$, where the large $\mathrm{T}$ antigen becomes inactive in these cells. It is tempting to speculate therefore that the signal for diffentiation provided by MAPK activation was insufficient to overcome the proliferative stimulus of active SV40 large $T$ antigen. However, after inactivating $T$ antigen by switching to $39^{\circ} \mathrm{C}$, increased levels of phosphorylated MAPKs in Bag1-expressing cells triggered differentiation into postmitotic neurons.

We observed a significantly increased doubling time of Bag1-expressing CSM14.1 cells even at permissive temperature where large $\mathrm{T}$ antigen is active. Similarly, Bag1 was reported to slow glioma cell growth both in control and under serum-deprived conditions. ${ }^{25}$ Recent findings support a role for Bag1 in cell growth regulation. ${ }^{13,27}$ Over-expression of Bag1, for example, can promote factor-independent growth of Interleukin 3-dependent lymphoid precursor cells ${ }^{7}$ and interfere with p53mediated cell cycle arrest in epithelial tumor cell lines. ${ }^{13}$ In this regard, it has been shown that Bag1 binds to the human homologue of Drosophila seven in absentia (Siah), ${ }^{13}$ a p53-inducible gene. ${ }^{30}$ Interestingly, in a transient transfection assay of the human kidney cell line 293T, overexpressed Siah-1 recruited Bag1 exclusively into the nucleus. ${ }^{13}$ Our data however argue that effects of Bag1 on cell proliferation are likely to be influenced by cellular background or lineage, given that Bag1 suppressed rather than stimulated growth of CSM14.1 neuronal cells. In line with this, Bag1 also failed to overcome p53-induced growth arrest in two human glioma cell lines. ${ }^{25,31}$

The reasons for differences in the effects of Bag1 protein over-expression on proliferation of neural versus epithelial or hematopoietic lineage cells are unknown, but a possible clue may come from contrasting the intracellular locations of this protein in cells. In the mouse, two isoforms of Bag1 have been described, with the shorter one studied here representing the more abundant gene product by far. ${ }^{22}$ The intracellular location of this Bag1 protein isoform may vary depending on cell background, environment and stage of differentiation, ${ }^{22,32}$ In CSM14.1 cells, we detected Bag1 transgene expression predominantly in the nucleus of undifferentiated CSM14.1 cells. In contrast, p29 Bag1 is reportedly found predominantly in the cytosol of epithelial and hematopoietic cells. ${ }^{7,22}$ After shifting CSM14.1 cells to nonpermissive temperature to allow differentiation, Bag1 protein accumulated in the cytosol over time, becoming absent from the nucleus. Accordingly, Bag1 presumably interacts with different molecular targets and exerts different effects depending on its intracellular location and cell type.

Interestingly, in the developing mouse nervous system, we found a similar situation with respect to Bag1 expression patterns, suggesting that Bag1 may modulate neuronal differentiation from a nuclear location. During neuronal differentiation in the mouse brain, Bag1 expression was highest in differentiating neuroblasts. Bag1 immunoreactivity was restricted to the nuclei of these cells, whereas low levels of cytosolic Bag1 were detected later in development in mature neurons. This shift of Bag1 expression from predominantly nuclear to mostly cytosolic, in parallel with neuronal maturation, was observed in all parts of the nervous system.

In summary, our results suggest a new function for Bag1 as a marker and regulator of neuronal differentiation. Future studies investigating the association of Bag1 expression with neuronal differentiation in vivo, particularly the generation of Bag1 transgenic and knock-out mice, should yield additional insights which might eventually be exploited for neuronal preservation or replacements after stroke, neurodegeneration, or other diseases.

\section{Materials and Methods}

\section{Plasmid constructions}

A plasmid was constructed for expression of flag-mouseBag1 (mBag1) under control of the neuron-specific enolase (NSE) promoter. First the $1.8 \mathrm{~kb} 5^{\prime}$-fragment of the rat NSE-promoter, ${ }^{24}$ kindly provided by $\mathrm{G}$ Sutcliffe, was subcloned into pBSKII using the EcoRI and HindlI restriction sites. In a second step, this plasmid was digested with $\mathrm{BamHI}$ and HindllI. The resulting NSE-promoter containing fragment was used to replace the HSV-TK promoter in pRL-TK (Promega) between the $B g l l$ and HindllI sites. The resulting construct containing a luciferase gene under the control of the NSE promoter served as control vector. Subsequently, flag-mBag1 was inserted at the Nhel and Notl sites from pCl-flag-mBag1. ${ }^{1}$

\section{Stable transfections}

The rat nigro-striatal cell line CSM14.1, immortalized by introduction of the temperature sensitive SV40 large $\mathrm{T}$ antigen, and a $\mathrm{Bcl}-2$ transfectant CSM $14.1-\mathrm{Bcl}-2^{23}$ were kindly provided by Dale Bredesen. Cells were maintained in Dulbecco's modified Eagle's medium (DMEM) supplemented with 10\% FBS (fetal bovine serum), $1 \mathrm{mM}$ L-glutamine, $100 \mathrm{U} / \mathrm{ml}$ penicillin, and $100 \mu \mathrm{g} / \mathrm{ml}$ streptomycin sulfate either in $32^{\circ} \mathrm{C}$ at permissive or $39^{\circ} \mathrm{C}$ at non-permissive temperature. ${ }^{23}$ For stable transfection, $50-70 \%$ confluent CSM cells in 6-well plates were incubated with Gene Porter II according to the supplier's protocol (Gene Therapy Systems) in serum-free medium containing $3 \mu \mathrm{g}$ of plasmid DNA representing a $5: 1$ ratio of specific plasmid:puromycin-resistance plasmid (pBabe-puro). After $3 \mathrm{~h}$ at $37^{\circ} \mathrm{C}$, serum-containing medium was added and the cells were incubated overnight. Finally, the transfection agent was replaced by $10 \%$ serum-containing medium and the cells were transferred to $32^{\circ} \mathrm{C}$. Selection with $4 \mu \mathrm{g}$ puromycin in complete medium was started the next day. After 5 days, 0.5 cells per well were seeded in 96 -well plates with selection medium, and 3 to 4 weeks later wells containing single clones were identified by light microscopy and the cells transferred to larger plates for expansion and further processing.

\section{Cell death, cell division assays and measurement of neurite outgrowth}

Cell death was induced by serum deprivation as published previously. ${ }^{23} 10^{5}$ cells were plated in 6-well plates and maintained in $39^{\circ} \mathrm{C}$. Prior to serum deprivation, cells were washed three times in serum-free medium. Cell death was assessed by Trypan Blue exclusion after $24 \mathrm{~h}, 2,3$, and 4 days in serum starvation. Experiments were repeated six times. 
Doubling times were determined during logarithmic growth in 24-well plates. $10^{4}$ cells were plated and daily cell counts were performed by Trypan Blue exclusion assay for 1 week.

The length of outgrowing neurites was assessed on day 8 at $39^{\circ} \mathrm{C}$ in three independent experiments on randomly picked cells using ImagePro-Plus software.

Statistics were performed using two-tailed Student's $t$-test.

\section{Antibodies}

Polyclonal antisera for Bag1 were generated in rabbits using synthetic peptides or GST-fusion protein immunogens. A peptide (NH2CNERYDLLVTPQQNSEPVVQD-amide) corresponding to residues 26-45 of the mouse Bag1 protein, was synthesized with an $\mathrm{N}$ terminal cysteine appended to permit conjugation to maleimideactivated carrier proteins KLH and OVA (Pierce, Inc.), as described previously. ${ }^{33}$ This peptide conjugate was used to generate a polyclonal antiserum (\#1735) in rabbits. ${ }^{22}$ An additional anti-Bag1 serum (\#1680) was generated in rabbit using a GST-mouse Bag1 (8219) fusion protein. ${ }^{1}$ The generation and characterization of a rabbit anti-mouse Bag1 antiserum targeted against amino acids $204-219$ (\#1702) have been described. ${ }^{1}$

\section{Immunoblot assays and immunofluorescence}

Cell lysates were prepared at different times after switching cells to non-permissive temperature using RIPA buffer as described. ${ }^{34}$ Proteins $(20 \mu \mathrm{g}$ per lane) were resolved by SDS-PAGE and transferred onto nitrocellulose membranes. After blocking with $5 \%$ skim milk, $2 \%$ bovine serum albumin (BSA) in TBST (10 mM Tris [pH 7.5]; $142 \mathrm{mM} \mathrm{NaCl} ; 0.1 \%$ Tween-20) at room temperature for $2 \mathrm{~h}$, blots were incubated in the same solution with various primary antibodies including polyclonal antisera against Bag1 (Bur 1735 and Bur 1680; 1:1000; see above), phospho-Erk1/2 and Erk1/2 (Cell Signaling; $1: 1000$ ), as well as monoclonal antibodies against Flag (Sigma M2 or M5; $3 \mu \mathrm{g} / \mathrm{ml}$ ) and Hsp70 (ABT; 1:5000), followed by horseradish peroxidase-conjugated anti-mouse or anti-rabbit IgG (Biorad) secondary antibodies. Bound antibodies were visualized using an enhanced chemiluminscence (ECL) detection system (Amersham).

For immunofluorescence, wild-type cells and those stably transfected with either empty vector or flag-mBag1 were trypsinized and seeded into chamber slides. Cells were either maintained in 32 or $39^{\circ} \mathrm{C}$ until further processing. After various lengths of time, cells were washed in PBS and fixed in PBS containing 4\% paraformaldehyde for 5 min at room temperature, followed by several washing steps in PBS. Permeabilization was performed in $0.3 \%$ Triton X-100/PBS for 5 min with subsequent preblocking in PBS containing $2 \%$ normal goat serum. Cells were incubated in blocking solution containing the following primary antibodies: Bur 1680 and 1735 (1:100), anti-Tubulin (1:2000), anti-Flag M5 (1:250), NeuN (Sigma, 1:50). After washing three times in PBS and incubation with FITC-conjugated secondary anti-mouse or anti-rabbit antibody (Dako, 1:50) for $2 \mathrm{~h}$ at room temperature, slides were covered with Vectashield mounting medium with or without $1.5 \mu \mathrm{g} / \mathrm{ml}$ 4,6-diamidino-2-phenylindole (DAPI) (Vector Laboratories) and sealed with Cytoseal 60 mounting medium (Stephens Scientific).

\section{Immunohistochemical analysis of mouse embryos}

The timing and distribution of Bag1 protein expression in the developing nervous system were assessed in paraffin sections derived from embryos and postnatal mice of the NMRI or FVB strains.
All procedures were approved by the institutional animal care committee. Prenatal development was studied on a closely spaced series of mouse embryos at daily intervals from 6 days or gestation (E6) to postnatal day 4 (P4). Twenty-five mice were studied at weekly intervals after that time until adulthood. Mice were mated overnight, and the morning the vaginal plug appeared was designated as embryonal day 0.5 (E0.5). The day of birth was termed as postnatal day zero (PO). All embryos were taken from mice which had been killed by over-dose of carbon dioxide. At E4-9, the uterus was excised and fixed with the embryos in situ. For the later embryos, each embryo was dissected from the uterus, freed from the extra-embryonic membranes and immediately placed in the fixatives, either Bouin's fixative, or zinc-buffered formalin (Z-fix; Anatech LTD, Battle Creek, MI, USA). Immersion time varied from 2 days for early stages to 5-7 days for fetal and postnatal specimens. Altogether, tissue specimens from 58 embryos and 29 mice after birth have been paraffin-embedded according to routine procedures.

Dewaxed tissue sections were exposed to polyclonal antibodies and confirmed to be specific for Bag1. The sections were immunostained using a diaminobenzidine (DAB)-based detection method as described in detail, employing either an avidin-biotin complex reagent (Vector Laboratories) or the Envision-Plus-Horse Radish Peroxidase (HRP) system (DAKO) using an automated immunostainer (Dako Universal Staining System. ${ }^{33,35}$ The dilutions of antisera typically employed were $1: 3500(\mathrm{v} / \mathrm{v})$ for \#1735, 1:5000 for $\# 1680$, and 1:2500 for \#1702.

To verify specificity of the results, the immunostaining procedure was performed in parallel using preimmune serum or anti-Bag1 antiserum preadsorbed with $5-10 \mu \mathrm{g} / \mathrm{ml}$ of synthetic peptide immunogen.

\section{Acknowledgements}

We thank Dale Bredesen, Buck Center (Novado, CA, USA), for providing CSM cells, Gregor Sutcliffe, Scripps Institute (La Jolla, CA, USA) for the NSE-containing plasmid, Jesus Velasco for technical support, April Sawyer and Rachel Cornell for manuscript preparation. P Kermer was supported by the Deutsche Forschungsgemeinschaft (Ke781/1-1). This work was supported by NIH grants (NS36821, CA-67329, AG15393).

\section{References}

1. Takayama S, Sato T, Krajewski S, Kochel K, Irie S, Millan JA and Reed JC (1995) Cloning and functional analysis of Bag-1: a novel Bcl-2 binding protein with anticell death activity. Cell 80: 279-284

2. Takayama S, Xie Z and Reed J (1999) An evolutionarily conserved family of Hsp70/Hsc70 molecular chaperone regulators. J. Biol. Chem. 274: 781-786

3. Takayama S and Reed JC (2001) Molecular chaperone targeting and regulation by BAG family proteins. Nature Cell Biol. 3: E237-E241

4. Zeiner M and Gehring U (1995) A protein that interacts with members of the nuclear hormone receptor family: identification and cDNA cloning. Proc. Natl. Acad. Sci. USA 92: 11465-11469

5. Bardelli A, Longati P, Albero D, Goruppi S, Schneider C, Ponzetto C and Comoglio PM (1996). HGF receptor associates with the anti-apoptotic protein BAG-1 and prevents cell death. EMBO J. 15: 6205-6212

6. Wang H-G, Takayama S, Rapp UR and Reed JC (1996) Bcl-2 interacting protein, BAG-1, binds to and activates the kinase Raf-1. Proc. Natl. Acad. Sci. USA 93: 7063-7068

7. Clevenger CV, Thickman K, Ngo W, Chang W-P, Takayama S and Reed JC (1997) Role of Bag-1 in the survival and proliferation of the cytokine-dependent lympocyte lines, Ba/F3 and Nb2. Mol. Endocrinol. 11: 608-618 
8. Danen-van Oorschot AA, den Hollander A, Takayama S, Reed JC, van der Eb AJ and Noteborn MH (1997) BAG-1 inhibits p53-induced but not apoptin-induced apoptosis. Apoptosis 2: 395-402

9. Schulz JB, Bremen D, Reed JC, Lommatzsch J, Takayama S, Wullner U, Loschmann P-A, Klockgether T and Weller M (1997) Cooperative interception of neuronal apoptosis by BCL-2 and BAG-1 expression: prevention of caspase activation and reduced production of reactive oxygen species. J. Neurochem. 69: 2075-2086

10. Takaoka A, Adachi M, Okuda H, Sato S, Yawata A, Hinoda Y, Takayama S, Reed $\mathrm{JC}$ and Imai K (1997) Anti-cell death activity promotes pulmonary metastasis of melanoma cells. Oncogene 14(24): 2971-2977

11. Liu R, Takayama S, Zheng Y, Froesch B, Chen G-Q, Zhang X, Reed JC and Zhang X-K (1998) Interaction of BAG-1 with retinoic acid receptor and its inhibition of retinoic acid-induced apoptosis in cancer cells. J. Biol. Chem. 273: $16985-16992$

12. Kullman M, Schneikert J, Moll J, Heck S. Zeiner M, Gehring U and Cato ACB (1998) RAP46 is a negative regulator of glucocorticoid receptor action and hormone induced apoptosis. J. Biol. Chem. 273(23): 14620-14625

13. Matsuzawa S, Takayama S, Froesch BA, Zapata JM and Reed JC (1998) p53inducible human homologue of Drosophila seven in absentia (Siah) inhibits cell growth: suppression by BAG-1. EMBO J. 17: 2736-2747

14. Froesch BA, Takayama S and Reed JC (1998) BAG-1L protein enhances androgen receptor function. J. Biol. Chem. 273: 11660-11666

15. Yenari MA, Giffard RG, Sapolsky RMand Steinberg GK (1999) The neuropeptide potential of heat shock protein 70 (HSP70). Molec. Med. Today 5: 525-531

16. Sharp FR, Massa SM and Swanson RA (1999) Heat-shock protein protection. Trends Neurosci. 22: 97-99

17. Takayama S, Bimston DN, Matsuzawa S, Freeman BC, Aime-Sempe C, Xie Z, Morimoto RJ and Reed JC (1997) BAG-1 modulates the chaperone activity of Hsp70/Hsc70. EMBO J. 16: 4887-4896

18. Crocoll A, Blum M and Cato ACB (2000) Isoform-specific expression of BAG-1 in mouse development. Mechanisms of Development 91: 355-359

19. Eversole-Cire P, Concepcion FA, Simon MI, Takayama S, Reed JC and Chen J (2000) Synergistic effect of Bcl-1 and BAG-1 on the prevention of photoreceptor cell death. Invest. Ophthalmol. Vis. Sci. 41: 1953-1961

20. Hayashi T, Sakai K, Sasaki C, Itoyama Y and Abe K (2000) Loss of bag-1 immunoreactivity in rat brain after transient middle cerebral artery occlusion. Brain Res. 82: 496-500

21. Sourisseau T, Desbois C, Debure L, Bowtell DD, Cato AC, SchneikertJ, MoyseE and Michel D (2001) Alteration of the stability of Bag-1 protein in the control of olfactory neuronal apoptosis. J. Cell Sci. 114: 1409-1416

22. Takayama S, Krajewski S, Krajewski M, Kitada S, Zapata JM, Kochel K, Knee D, Scudiero D, Tudor G, Miller GJ, Miyashita T, Yamada M and Reed JC (1998) Expression and location of Hsp70/Hsc-binding anti-apoptotic protein BAG-1 and its variants in normal tissues and tumor cell lines. Cancer Res. 58: 3116-3131
23. Zhong LT, Sarafian T, Kane DJ, Charles AC, Mah SP, Edwards RH and Bredesen DE (1993) Bcl-2 inhibits death of central neural cells induced by multiple agents. Proc. Natl. Acad. Sci. USA 90: 4533-4537

24. Forss-Petter S, Danielson PE, Catsicas S, Battenberg E, Price J, Nerenberg M and Sutcliffe JG (1990) Transgenic mice expressing beta-galactosidase in mature neurons under neuron-specific enolase promoter control. Neuron 5 : $187-197$

25. Roth W, Grimmel C, Rieger L, Strik H, Takayama S, Krajewski S, Meyermann R, Dichgans J, Reed JC and Weller M (2000) Bag-1 and Bcl-2 gene transfer in malignant glioma: modulation of cell cycle regulation and apoptosis. Brain Pathol. 10: 223-234

26. Morrison DK and Cutler RE (1997) The complexity of Raf-1 regulation. Curr. Opin. Cell Biol. 9: 174-179

27. Song J, Takeda Mand Morimoto RI (2001)Bag1-Hsp70 mediates a physiological stress signaling pathway that regulates Raf-21/ERK and cell growth. Nature Cell Biol. 3: 276-282

28. Avruch J, Khokhlatchev A, Kyriakis JM, Luo Z, Tzivion G, Vavvas D and Zhang ZF (2001) Ras activiation of the Raf kinase: tyrosine kinase recruitment of the MAP kinase cascade. Recent Prog. Horm. Res. 56: 127-55

29. Sweatt JD (2001) The neuronal MAP kinase cascade: a biochemical signal integration system subserving synaptic plasticity and memory. J. Neurochem. 76: $1-10$

30. Amson RB, Nemani M, Roperch J-P, Israeli D, BougueleretL, Le Gall I, Medhioub $M$, Linares-Cruz G, Lethrosne F, Pasturaud P, Piouffve L, Prieur S, Susini L, Alvaro V, Millasseau P, Guidicelli C, Bui H, Massart C, Cazes L, Dufour F, Bruzzoni-Giovanelli H, Owadi H, Hennion C, Charpak G, Dausset J, Calvo F, Oren M, Cohen D and Telerman A (1996) Isolation of 10 differentially expressed cDNAs in p53-induced apoptosis: activation of the vertebrate homologue of the Drosphilia seven in absentia gene. Proc. Natl. Acad. Sci. USA 93: 3953-3957

31. Van Meir EG, Kikuchi T, Tada M, Li H, Diserens AC, Wojcik BE, Huang HJ, Friedmann T, de TN and Cavenee WK (1994). Analysis of the p53 gene and its expression in human glioblastoma cells. Cancer Res. 254: 649-652

32. Nollen EA, Brunsting JF, Song J, Kampinga HH and Morimoto RI (2000) Bag1 functions in vivo as a negative regulator of Hsp70 chaperone activity. Mol. Cell Biol. 20: 1083-1088

33. Krajewski S, Krajewska M, Shabaik A, Miyashita T, Wang H-G and Reed JC (1994) Immunohistochemical determination of in vivo distribution of bax, a dominant inhibitor of Bcl-2. Am. J. Pathol. 145: 1323-1333

34. Krajewski S, Mai JK, Krajewska M, Sikorska M, Mossakowski MJ and Reed JC (1995) Upregulation of Bax protein levels in neurons following cerebral ischemia. J. Neuorsci. 15: 6364-6376

35. Krajewski S, Krajewska M, Ellerby LM, Welsch K, Xia Z, Deveraux QL, Salvesen GS, Bredesen DE, Rosenthal RE, Fiskum G and Reed JC (1999) Release of caspase-9 from mitochondria during neuronal apoptosis and cerebral ischemia. Proc. Natl. Acad. Sci. USA 96: 5752-5757 